\title{
Modulation of ERK1/2 activity is crucial for sphingosine-induced death of glioma C6 cells
}

\author{
Patryk Krzemiński ${ }^{凶}$ \\ Laboratory of Signal Transduction, Department of Cellular and Molecular Neurobiology, Nencki Institute of \\ Experimental Biology, Warszawa, Poland; ${ }^{\circledR}$-mail: pkrzemin@nencki.gov.pl
}

Received: 07 July, 2005; revised: 19 October, 2005; accepted: 20 October, 2005

available on-line: 21 November, 2005

\begin{abstract}
In this study the contribution of the ERK1/2 pathway to sphingosine-induced death and morphological changes of the actin cytoskeleton in glioma C6 cells was investigated. Surprisingly, the level of ERK1/2 phosphorylation does not change after incubation of cells with sphingosine. Despite this, sphingosine induces rounding and detachment of cells without formation of apoptotic bodies. To shed light on this process, a specific inhibitor of ERK1/2 phosphorylation, U0126, was used. Cells incubated simultaneously with sphingosine and U0126 not only detached, but also exhibited formation of apoptotic-like blebs. These data suggest that during sphingosine-induced glioma C6 cell death apoptotic blebbing is dependent on ERK1/2 signalling and occurs only when ERK $1 / 2$ activity is decreased or abolished.
\end{abstract}

Keywords: programmed cell death, cytoskeleton, ERK1/2, glioma C6

Many natural and pathological cellular processes, including migration, invasion, cell division and apoptosis are well understood in general. However, some aspects of these processes are still unclear. One of them is formation of apoptotic bodies. Dying cells exhibit a number of ordered phases, including loss of mitochondrial potential, externalization of phosphatidylserine, fragmentation of DNA and finally formation of apoptotic bodies (Kerr et al., 1972; Green, 1998). Especially this last event differentiates typical apoptosis from other types of cell death. Cells that undergo apoptosis can be eliminated in a different way than cells which do not exhibit blebbing. A lack of bleb formation following creation of apoptotic bodies often leads to impaired cell removal. Causes of cell death without creation of blebs are still unclear. One reason could be weak activation of prosurvival pathways in the dying cells (Miller \& Kaplan, 2001; Burstein \& Ducket, 2003; Wajant et al., 2003).

Experiments described in this paper are focused on sphingosine, a specific compound that combines proapototic and prosurvival features. This makes it possible to investigate the situation when cells are under the influence of those two opposing signals.
Sphingosine is an essential carboamnioalcohol normally present in the cell membranes (Spiegel et al., 1998). It has been proven that in higher than physiological concentration sphingosine induces death in many cell types (Cuvillier, 2002). Exogenously added, it alters the precise balance between sphingosine-1-phosphate and ceramide, the products of sphingosine catabolism. Sphingosine-1-phosphate is known for its antiapoptotic effect, while cermide as well as sphingosine itself can induce death (Sweeney et al., 1996; Stoica et al., 2003). All derivates of sphingosine influence the MAPK pathway (Sato et al., 1999; Pebay et al., 2001) and have an effect on cytoskeleton rearrangement (Van Brocklyn et al., 1999; Chang et al., 2004). One of the most important members of MAPK is ERK1/2, involved in both survival and cell death (Freeman, 2004). Decreased phosphorylation of ERK is observed in most cases of apoptotic death. On the contrary, ERK1/2 activation is often considered as a sign of escape from the death course. Sphingosine itself and its derivatives can have activatory as well as inhibitory effects on that kinase. Therefore, experiments described in this paper are focused on death processes induced by sphingosine with a special attention on

Abbreviations: CDS, cell dissociation solution; DAPI, 4',6-diamidino-2-phenylindole; ECL, chemiluminescence detection system; ERK, extracellular signal-regulated; MEK, MAPK/ERK kinase; NCS, newborn calf-serum; PBS, phosphate-buffered saline; $\mathrm{SPH}$, sphingosine. 
its role in the modulation of the ERK1/2 pathway in glioma C6 cells.

\section{MATERIALS AND METHODS}

Materials. Minimum essential medium (MEM), newborn calf serum (NCS), antibiotics, MEM vitamins, MEM nonessential amino acids and phosphate-buffered saline (PBS) were from Gibco BRL. Mounting medium with 4',6-diamidino-2-pheylindole (DAPI) was from VectaShield (Bourlingame, CA, USA). ALEXAfluo488 conjugated with phalloidine was from Molecular Probes. Complete EDTAfree protease inhibitors were from Roche. Antibodies recognizing phosphorylated p44/42 MAP kinase (Erk1/2; Thr202/Tyr204) and horseradish peroxidaseconjugated anti-rabbit IgG were from Cell Signalling. Horseradish peroxidase-conjugated anti-mouse IgG antibodies and antibodies against $\beta$-actin were from Oncogene Research Products. Nitrocellulose membrane and enhanced chemiluminescence detection system (ECL) were from Amersham Pharmacia Biotech. All other reagents were purchased from Sigma Chemical Co. Medical X-ray films were from FOTON TRADING Poland.

Cell culture. Rat C6 glioma cells (American Type Culture Collection) were cultured in MEM supplemented with 10\% NCS, penicillin (50 IU), streptomycin $(10 \mu \mathrm{g} / \mathrm{ml})$, amphotericin B $(25 \mu \mathrm{g} / \mathrm{ml})$ and $2 \mathrm{mM}$ L-glutamine in a humidified atmosphere of $5 \% \mathrm{CO}_{2}$ at $37^{\circ} \mathrm{C}$. For experiments, cells were cultivated in the full MEM supplemented with $10 \%$ NCS to reach $90 \%$ confluence. In the case of sphingosineor U0126-treated cells, the medium was changed to MEM without NCS, and then sphingosine diluted in NCS or U0126 diluted in DMSO were added.

DAPI staining. Intact cells grown on glass cover slips (85\% of confluence) were washed with PBS and fixed with $3.5 \%$ paraformaldehyde in PBS for $30 \mathrm{~min}$ at room temperature. This was followed by PBS rinse and permeabilization with $0.1 \%$ Triton X-100 in PBS. After two washes with PBS, staining with DAPI was accomplished by mounting the cover slips in mounting medium containing DAPI. Nuclear morphology was visualized by fluorescence microscopy using excitation at 330-380 $\mathrm{nm}$ and emission at $>450 \mathrm{~nm}$. The observations were performed with a Nikon Diaphot inverted microscope equipped with a 40/0.55 LWD objective lens. All image processing was done in the Adobe Photoshop 6.0 program.

Staining for filamentous actin. Intact cells grown on glass cover slips (85\% of confluence) were washed, fixed and permeabilized as described above. After two washes with PBS, staining for filamentous actin was accomplished by incubation with 1\% ALEXAFLUO488-conjugated phalloidin for 30 min. Then, after two washes in PBS cells were mounted in VectaShield mounting medium. $\beta$-Actin morphology was visualized by fluorescence microscopy using excitation at $490-515 \mathrm{~nm}$ and emission at $550 \mathrm{~nm}$. The observations and image processing was done as above.

Western blot analysis. For the experiments cells were grown up to $85 \%$ confluency on $10 \mathrm{~mm}$ dishes in MEM+ $10 \%$ NCS. In order to cause serum deprivation, the medium was replaced by fresh serum-free medium (MEM-) for $96 \mathrm{~h}$. After this time, the medium was changed for $24 \mathrm{~h}$ to fresh serumfree medium containing appropriate concentrations of either agonist or antagonist. At the end of the experiment cells were washed in PBS, detached by 3 min CDS (cell dissociation solution) treatment, centrifuged at 3000 r.p.m. for $5 \mathrm{~min}$ and then resuspended in lysis buffer containing: 1\% Nonidet P-40, $120 \mathrm{mM} \mathrm{NaCl}, 50 \mathrm{mM}$ Tris/ $\mathrm{HCl}, \mathrm{pH}$ 7.5, and freshly added proteinase inhibitors. Separation of proteins was performed on $12 \%$ polyacrylamide SDS/PAGE. Proteins were transferred to nitrocellulose membranes (Hybond C, Amersham Pharmacia Biotech, Milan, Italy), blocked for $1 \mathrm{~h}$ at room temperature with 5\% milk in PBS-T (phosphate-buffered saline $\mathrm{pH} 7.6 / 0.005 \%$ Tween 20), and incubated overnight at $4^{\circ} \mathrm{C}$ with the antisera against: $\beta$-actin and $\mathrm{p} 42 / \mathrm{p} 44$ phospho-ERK (both 1:5000), (Cell Signalling) diluted in $1 \%$ nonfat milk in PBS-T. The primary antibody reaction was followed by $2 \mathrm{~h}$ incubation with relevant secondary (1:2500) antibody.

Immunocomplexes were detected using the ECL-enhanced chemiluminescence detection system (Amersham Pharmacia Biotech) and membrane exposure to X-ray film (FOTON). The molecular weight of proteins was estimated with prestained protein markers (Fermentas protein ladder). Band intensities were determined by densitometry analysis in an Ingenius station using provided programs. Only statistically significant immunoblot band intensity data are reported.

\section{RESULTS AND DISCUSSION}

There is evidence that sphingosine $(\mathrm{SPH})$ can induce cell death in the apoptotic manner, however, little is known about its effect on glioma cells. In this study, glioma C6 cells were treated with $250 \mu \mathrm{M}$ sphingosine for $120 \mathrm{~min}$ and then the distribution of filamentous actin (f-actin) was observed. Incubation time and $\mathrm{SPH}$ concentration were chosen on the basis of results of several preliminary experiments (not shown). As illustrated, SPH strongly altered the morphology of glioma C6 actin cytoskeleton (Fig. 1C). After 120 min of incubation with SPH cells which were normally flat and well attached (Fig. 1A) became rounded and started to detach (Fig. 1C). Interestingly, the nuclei remained untouched and no 

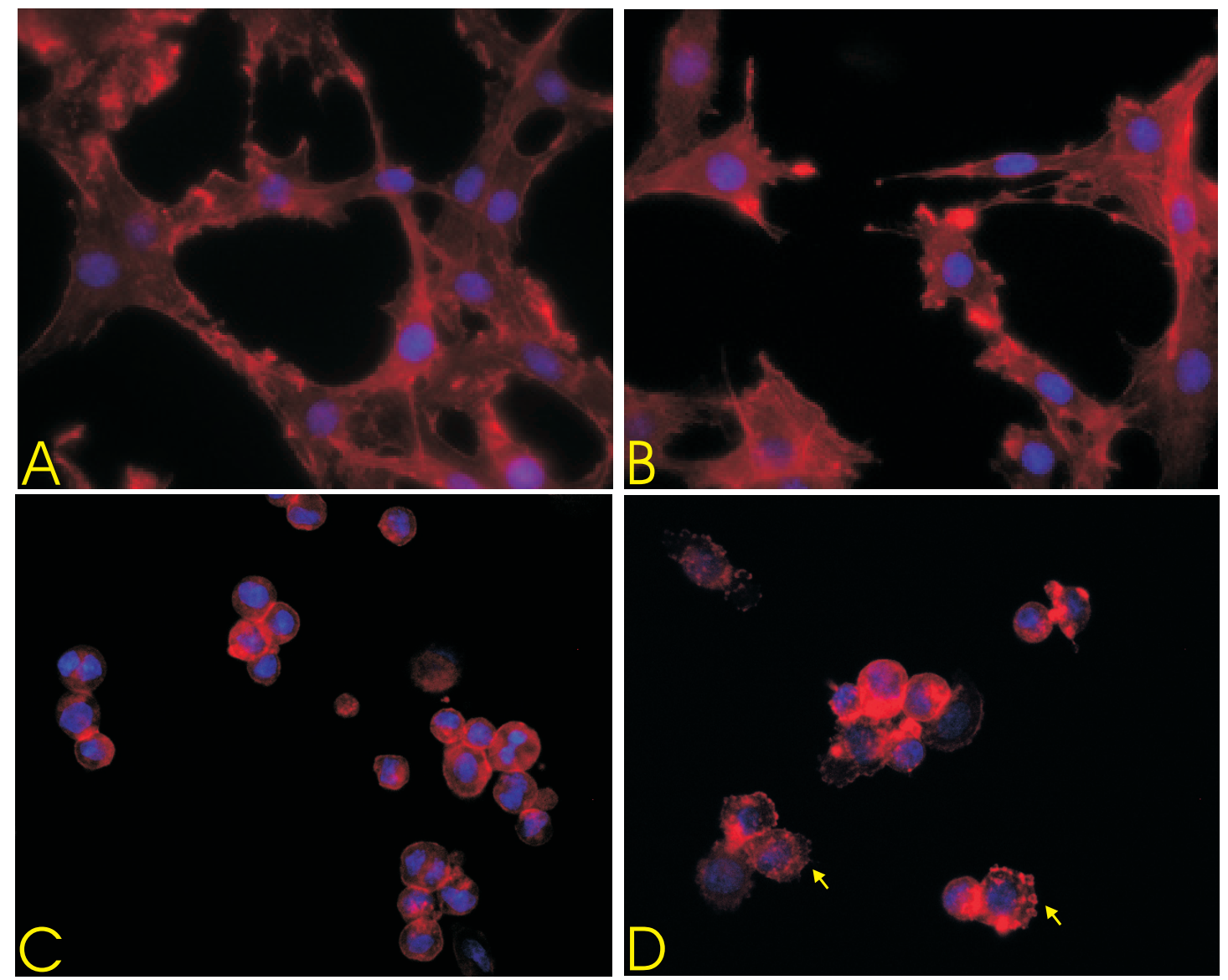

Figure 1. Changes in the morphology and organization of filamentous actin in glioma C6 cells.

Filamentous actin was stained with phalloidine-ALEXAFLUO488 (red) and the nuclei were stained with DAPI (blue). A, untreated cells; B, cells incubated for 120 min with ERK1/2 phosphorylation inhibitor, U0126 $(2 \mu \mathrm{M})$; C, cells incubated for 120 min with SPH $(250 \mu \mathrm{M})$; D, cells incubated for 120 min with $250 \mu \mathrm{M}$ SPH and $2 \mu \mathrm{M}$ U0126. Yellow arrows indicate marginal bleb formation on cells treated simultaneously with SPH and U0126.

changes in chromatin condensation typical for apoptosis were observed. Moreover, no signs of bleb formation could be noticed (Fig. 1C). Nevertheless, when floating cells were collected and reseeded on a Petri dish in fresh medium, after 24 and $48 \mathrm{~h}$ none of them attached to the dish surface and started to grow normally (not shown). An explanation of such a situation might come from the fact that sphingosine is a substrate for enzymes catalyzing its conversion to sphingosine-1-phosphate and ceramide. Both these compounds could influence phosphorylation of ERK1/2.

It is generally accepted that the ERK1/2 pathway plays an important role in integrating many cellular processes, including cell proliferation and cell death (Bhaskara et al., 2005; Engelbrecht et al., 2005). It has been also shown that ERK1/2 may be inhibited as well as activated during programmed cell death, depending on the cell line and the type of lethal agent (Amran, 2005). Sphingosine-1-phosphate is known from its antiapoptotic properties and enhances the activity of ERK1/2 in many cell lines (Harada et al., 2004; Lockman et al., 2004). On the other hand, ceramide is a well known proapoptotic agent (Dawson et al., 1998; Pascual et al., 2003), however, in some cases it induces atypical cell death (Mengubas et al., 1999; Daido et al., 2004). To gain more information about the processes induced by sphingosine, the level of phosphorylated ERK1/2 was monitored. As can be noticed in Fig. 2, Western blot analysis with specific antibodies raised against phosphorylated active form of ERK1/2 revealed no significant differences in the phosphorylation of that kinase. These results suggest that sphingosine treatment does not influence the activation level of ERK1/2 (Fig. 2).

In order to find out if ERK1/2 participates in processes induced by sphingosine, a specific inhibitor of ERK1/2 phosphorylation, U0126, was employed. U0126 has been shown to be a highly selective inhibitor of the MEK1 and MEK2 kinases that phosphorylate ERK1/2 (Favata et al., 1998). ERK1/2 deactivation that is caused by MEK $1 / 2$ inhibition can often intensify apoptosis or force cells to die in the apoptotic manner. As shown in Fig. 1B, incubation with the inhibitor alone did not induce any characteristic changes in cell actin morphology, however, it strongly inhibited the level of active ERK1/2 (Fig. 2). In contrast, simultaneous administration of $\mathrm{SPH}$ and U0126 resulted in the appearance of marginal 


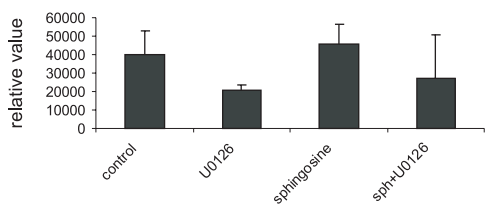

$120^{\prime}$

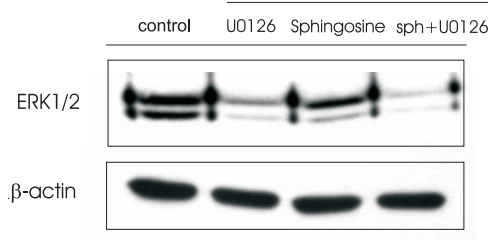

Figure 2. Effect of SPH and U0126 on p44/p42 ERK1/2 phosphorylation.

C6 cells were grown as described in Methods. Control, untreated cells; U0126, cells incubated for $120 \mathrm{~min}$ with ERK1/2 phosphorylation inhibitor, U0126 $(2 \mu \mathrm{M})$; sphingosine, cells incubated for 120 min with $\mathrm{SPH}(250 \mu \mathrm{M})$; SPH and U0126, cells incubated for 120 min with $250 \mu \mathrm{M}$ SPH and $2 \mu \mathrm{M}$ U0126. The cells were lysed in SDS sample buffer and subjected to standard Western blot analysis using anti-phospho-p44/p42 MAPK polyclonal antibody. The bands were visualized by ECL method and quantified using Ingenius software. $\beta$-Actin was used as a control of equal amounts of protein samples. The columns represent phosphorylation of both ERK1 and ERK2. The results are expressed as the means \pm S.D. from three independent experiments.

blebs on detaching cells (Fig. 1D), similar to those observed by the group of Domnina (Domnina et al., 2004), and at the same time decreased the level of phosphorylated ERK1/2 (Fig. 2). Although such a situation could precede further apoptotic steps, no other changes characteristic for apoptosis, like, e.g., chromatin condensation were observed (Fig. 1D). Also, the time needed for detachment remained unchanged. These results provide evidence that beginning of the sphingosine-induced bleb formation may depend on deactivation of the ERK1/2 kinase.

In conclusion, this study shows that constant, high ERK1/2 activity leads to the preservation of membrane structure even in rounding and detaching cell, whereas decreased phosphorylation of ERK1/2 allows cells to form marginal blebs. Thus, the formation of blebs in SPH-induced glioma C6 death depends on ERK $1 / 2$ deactivation. It is worth adding that there is little evidence concerning the mechanisms of bleb formation. A lack of blebbing may often be responsible for atypical cell death and sometimes might also cause difficulties in eliminating the dying cells in vivo. Data presented in this paper shed light on blebs formation, a step of programmed death, and provide valuable basis for further studies.

\section{Acknowledgements}

The author expresses his gratitude to Prof. Jolanta Barańska (Nencki Institute) for helpful discussion.

\section{REFERENCES}

Amran D (2005) Biochim Biophys Acta 15: 269-279.

Bhaskara VK, Panigrahi M, Challa S, Babu PP (2005) Neuropathology 25: 48-53.

Boldt S, Weidle UH, Kolch W (2002) Carcinogenesis 23: 1831-1838.

Burstein E, Duckett CS (2003) Curr Opin Cell Biol 15: 732737.

Chang SE, Kim KJ, Ro KH, Lim YJ, Choi JH, Moon KC, Sung KJ (2004) J Dermatol 31: 1-5.

Cuvillier O (2002) Biochim Biophys Acta 1585: 153-162.

Daido S, Kanzawa T, Yamamoto A, Takeuchi H, Kondo Y, Kondo S (2004) Cancer Res 64: 4286-4293.

Dawson G, Goswami R, Kilkus J, Wiesner D, Dawson S (1998) Acta Biochim Polon 45: 287-297.

Domnina LV, Ivanova OY, Pletjushkina OY, Fetisova EK, Chernyak B, Skulachev VP, Vasiliev JM (2004) Cell Biol Int 28: 471-475.

Engelbrecht AM, Gebhardt S, Louw L (2005) Cancer Lett (available on line May 31).

Fang JY, Richardson BC (2005) Lancet Oncol 6: 322-327.

Favata MF, Horiuchi KY, Manos EJ, Daulerio AJ, Stradley DA, Feeser WS, Van Dyk DE, Pitts WJ, Earl RA, Hobbs F, Copeland RA, Magolda RL, Scherle PA, Trzaskos JM (1998) J Biol Chem 273: 18623-18632.

Freeman SM (2004) Drug News Perspect 17: 237-242.

Green DR (1998) Cell 94: 695-698.

Harada J, Foley M, Moskowitz MA, Waeber C (2004) J Neurochem 88: 1026-1039.

Kerr JFR, Wyllie AH, Currie AR (1972) Br J Cancer 26: 239257.

Lockman K, Hinson JS, Medlin MD, Morris D, Taylor JM, Mack CP (2004) J Biol Chem 279: 42422-42430.

Mengubas K, Riordan FA, Bravery CA, Lewin J, Owens DL, Mehta AB, Hoffbrand AV, Wickremasinghe RG (1999) Oncogene 18: 2499-2506.

Miller F, Kaplan DR (2001) Cell Mol Life Sci 58: 1045-1053.

Pascual M, Valles SL, Renau-Piqueras J, Guerri C (2003) J Neurochem 87: 1535-1545.

Pebay A, Toutant M, Premont J, Calvo CF, Venance L, Cordier J, Glowinski J, Tence M (2001) Eur J Neurosc 13: 2067-2076.

Spiegel S, Cuvillier O, Edsall LC, Kohama T, Menzeleev R, Olah Z, Olivera A, Pirianov G, Thomas DM, Tu Z, Van Brocklyn JR, Wang F (1998) Ann N Y Acad Sci 845: 11-18.

Stoica BA, Movsesyan VA, Lea PM, Faden AI (2003) Mol Cell Neurosci 22: 365-382.

Sweeney EA, Sakakura C, Shirahama T, Masamune A, Ohta H, Hakomori S, Igarashi Y (1996) Int J Cancer 66: 358-366.

Van Brocklyn JR, Tu Z, Edsall LC, Schmidt RR, Spiegel S (1999) J Biol Chem 274: 4626-4632.

Wajant H, Pfizenmaier K, Scheurich P (2003) Cytokine Growth Factor Rev 14: 53-66. 